\title{
Experimental design for optimization of D-lactic acid production using a UV-light selected strain
}

\begin{abstract}
Lactic acid is a molecule with several applications in different industries. Many applications require high isomeric purity, in order to attain the need properties of the final product. L-lactic acid production has already been extensively studied, however, D-lactic acid production remains a challenge since the majority of the strains used in lactic acid production are L producers. Bearing all this in mind, this study presents UV-light as an alternative tool to enhance D-lactic acid production. Different UV-light selected strains from $S \_$porolactobacillus nakayamae subsp. nakayamae were studied in order to obtain high D-lactic acid concentration. Preliminary tests were performed using different carbon and nitrogen sources. Further, an experimental design was used to optimize the medium composition. As result, the selected strain presented a better D-lactic acid production compared to the natural strain, with $97 \%$ of isomeric purity. The maximal production of D-lactic acid reached $74.46 \mathrm{~g} / \mathrm{L}$ from clarified sugarcane juice and yeast extract, with a productivity of $3.10 \mathrm{~g} / \mathrm{Lh}$.
\end{abstract}

Keywords: D-lactic acid, UV-light, S_porolactobacillus nakayamae, experimental design, optimization
Volume 5 Issue 4 - 2018

\author{
Regiane Alves de Oliveira,' Luciana Fontes \\ Coelho, ${ }^{2}$ Natalia Sozza Bernardi, ${ }^{3}$ Jonas \\ Contiero $^{2}$ \\ 'Department of Processes and Products Development, \\ University of Campinas (Unicamp), Brazil \\ ${ }^{2}$ Department of Biochemistry and Microbiology, Universidade \\ Estadual Paulista "Julio de Mesquita Filho" (UNESP), Brazil \\ ${ }^{3}$ Department of Pharmaceutical Technology, University of \\ Coimbra, Portugal
}

\begin{abstract}
Correspondence: Jonas Contiero, Department of Biochemistry and Microbiology, Universidade Estadual Paulista (UNESP), Avenida 24A, I5I 5, Bela Vista, 13506-900, Rio ClaroSP, Brazil,Tel +55 19 35264l80, Email jconti@rc.unesp.br
\end{abstract}

Received: July 18, 2018 | Published: August 22, 2018

\section{Introduction}

Lactic acid (LA) is an organic acid with a hydroxyl and an acid functional group. ${ }^{1,2}$ It can be produced by humans, plants, animals and microorganisms. ${ }^{2}$ It has an asymmetric carbon and it naturally occurs as two optical isomers, D- and L-LA, due to the existence of a chiral centre. ${ }^{1,3}$ It was discovered in 1780 by the experimental chemist Carl Wilhelm Scheele, isolated from sour milk. Currently is known as 2-hydroxypropanoic acid. ${ }^{4}$

LA chemical production leads to racemic mixtures of $\mathrm{D}$ and $\mathrm{L}$ isomers. ${ }^{5}$ This circumstance makes impossible to control the chemical and physical properties of the final product. Besides that, the racemic mixture is not suitable to be used in food, pharmaceutical, and medical industries. The proportion of each isomer confers different physical properties to the final product. It makes the enantiomeric purity a crucial factor for LA industrial production, as in the manufacture of biodegradable plastics and polymers as poly-LA. ${ }^{6}$

The polymerization of a racemic mixture of L- and D-LA generally leads to the synthesis of poly-DL-LA (PDLLA), which is amorphous. The crystallinity and many other important physical properties such as rate of degradation, ${ }^{3}$ melting and boiling point 1 are controlled by the ratio of enantiomers D and L used. ${ }^{3,7}$ Due to the chiral nature of the LA, several different types of polymers can be produced, for example, poly-L-LA (PLLA) is the product resulting from the polymerization of L-LA, which has high crystallinity and high melting point., ${ }^{4,8}$ The melting temperature of the PLLA may be increased to $50^{\circ} \mathrm{C}$ by the physical mixture with the polymer PDLA (poly-D-LA) which can form a highly regular stereo-complex with increased crystallinity and thermal stability. ${ }^{9,10}$

Due to the necessity of enantiomeric purity in the industries for some specific applications, the LA production by fermentation has been more attractive instead of chemical production. Currently, almost all LA in the world is produced by fermentation, ${ }^{11}$ however, the majority of the microorganisms used and most of the studies in the literature are focused on the L-LA biosynthesis. So far, cost-effective production of L-LA, used for PLLA production, is well established compared to that of D-LA, used for PDLA production, production process. ${ }^{12,13}$

This finding has led to increased interest in the production of optically pure D-LA because the commercial lactic acid market historically has been dominated by L-LA. ${ }^{10,14}$

Several microorganisms have been reported to be natural D-LA producers. ${ }^{15-17}$ Also, genetically engineered microorganisms have been reported to be pure D-LA producers. ${ }^{10,12,14,18-21}$ However, to the best of our knowledge, it is the first time that UV-light is used as a tool to enhance D-LA production.

Bearing all this in mind, the main objective of this study is to improve the D-LA production with high isomeric purity, using an isolated $S$ porolactobacillus nakayamae subsp. nakayamae submitted to UV-light mutation. It was also evaluated the effects of different media composition, such as different carbon and nitrogen sources on D-LA production.

\section{Methods}

\section{Microorganism}

The microorganism S_porolactobacillus nakayamae subsp. nakayamae Vini6 is gram-positive, rod-shaped, spore-forming, and a D-LA producer. It was isolated from Desmodium adscendens root. ${ }^{22}$ The strain was stored in GYP (Glucose-Yeast-Peptone) medium 23 with $20 \%$ glycerol (v/v) at $-20^{\circ} \mathrm{C}$.

The microorganism was cultivated in GYP culture medium and incubated at $35^{\circ} \mathrm{C}$ for 24 hours. Afterwards, the bacterial suspension was transferred to an Erlenmeyer flask at the same conditions and used as the inoculum. $10 \%$ of the workload was inoculated in all fermentation tests. 


\section{UV light mutation}

S. nakayamae subsp. nakayamae strain was cultivated in GYP media for 24 hours at $35^{\circ} \mathrm{C}$, thereafter it was transferred to solid $\mathrm{GYP}$ and incubated for 48 hours at $35^{\circ} \mathrm{C}$. The bacterial colonies were exposed to UV-light $(254 \mathrm{~nm})$ for 20 minutes. After that, $\mathrm{NaCl} 0.85 \%$ was added and the colonies were mixed. The aliquot was used in serial dilutions in solid GYP with $\mathrm{CaCO}_{3} 1 \%$ and incubated at $35^{\circ} \mathrm{C}$ for 48hours. Selection of colonies was based on rapid growth, as well as on the largest acid production halo. The selected colonies were mixed and incubated to grow and again exposed to UV irradiation for another 20 minutes. Three cycles of exposure to UV-light were performed.

\section{Fermentation}

All fermentation tests were performed in $40 \mathrm{~mL}$ Erlenmeyer flasks containing $20 \mathrm{~mL}$ of medium, at $35^{\circ} \mathrm{C}$ and $150 \mathrm{rpm}$. Initial $\mathrm{pH}$ was adjusted to 7.0 and $60 \mathrm{~g} / \mathrm{L}$ of $\mathrm{CaCO}_{3}$ was added before the inoculum, in order to control the $\mathrm{pH}$ during the fermentation time. All tests were performed in triplicate. Samples were stored at $-20^{\circ} \mathrm{C}$ to further analysis after the centrifugation to remove cells and $\mathrm{CaCO}_{3}$

For each test, LA production ( $\mathrm{g} / \mathrm{L})$, productivity (Equation 1$)$ and remaining total reducing sugar (RTRS) (Equation 2) were calculated to evaluate the process.

$$
\begin{aligned}
& P_{\left(\mathrm{g} L^{-1} h^{-1}\right)}=\frac{\text { lactic acid }_{(g / L)}}{\text { time }_{(h)}} \\
& R_{\operatorname{TRS}\left(\frac{g}{L}\right)}=T R S_{\text {initial }\left(\frac{g}{L}\right)}-T R S_{\text {final }}\left(\frac{g}{L}\right)
\end{aligned}
$$

\section{Carbon source determination}

The fermentation media was composed of $5 \mathrm{~g} / \mathrm{L}$ of sodium acetate, salts solution of GYP media $\left(4 \% \mathrm{MgSO}_{4} ; 0.2 \% \mathrm{MnSO}_{4} ; 0.2 \% \mathrm{FeSO}_{4}\right.$; and $0.2 \% \mathrm{NaCl}$ ), $30 \mathrm{~g} / \mathrm{L}$ of yeast extract and $100 \mathrm{~g} / \mathrm{L}$ of TRS (total reducing sugars) from four different carbon sources: sugarcane juice; clarified sugarcane juice; commercial glucose; commercial sucrose.

Clarified sugarcane juice was prepared using $\mathrm{Ca}(\mathrm{OH})_{2}$, as the method called simple defecation with lime and heating 24: sugarcane juice was limed with $\mathrm{Ca}(\mathrm{OH})_{2}$ to $\mathrm{pH} 8.0$ and placed in the water bath $105^{\circ} \mathrm{C}$ for 1 hour and afterwards filtered, in order to remove the solids.

\section{Nitrogen source determination}

The microorganism was incubated in culture media with $5 \mathrm{~g} / \mathrm{L}$ of sodium acetate, salts solution of GYP media, and $100 \mathrm{~g} / \mathrm{L}$ of TRS (total reducing sugars) from the best carbon source previous determined (item 2.4). Four different nitrogen sources were tested, as shown in Table 1: yeast extract, yeast autolyzed, corn steep liquor (CSL), and pro-floo (cottonseed protein). The statistical analysis was performed using Statistica 7.0 (Statsoft Inc). The results were submitted to F-test with the average results compared by Tukey's test.

Table I Nitrogen source concentration

\begin{tabular}{lll}
\hline Nitrogen source & Concentration A & Concentration B \\
\hline Yeast extract $(\mathrm{g} / \mathrm{L})$ & $\mathrm{I} 5$ & 30 \\
Yeast autolyzed $(\mathrm{g} / \mathrm{L})$ & 12.75 & 25.5 \\
CSL $(\mathrm{mL} / \mathrm{L})$ & 36.75 & 73.5 \\
Pro-floo (g/L) & 15.47 & 30.94 \\
\hline
\end{tabular}

The amount of each nitrogen source corresponds to the same amount of nitrogen contained in $15 \mathrm{~g} / \mathrm{L}$ and $30 \mathrm{~g} / \mathrm{L}$ of yeast extract. Concentration A corresponds to $1.725 \mathrm{~g}$ of nitrogen $/ \mathrm{L}$; Concentration $\mathrm{B}$ corresponds to $3.45 \mathrm{~g}$ of nitrogen $/ \mathrm{L}$.

\section{Experimental design}

In order to evaluate the influence of TRS, nitrogen source, sodium acetate and GYP salts solution for D-LA production, it was performed a factorial central composite design with four replicates at the central point, totalizing 28 experiments. Table 2 shows concentrations and levels of the 4 independent variables analysed. The Statistic 7.0 (Statsoft Inc.) was used to analyse the experimental design. The confidence level for the regression test was fixed at $95 \%$. The results were submitted to the F-test and the average results compared by Tukey's test.

Table 2 Real values of the coded independent variables

\begin{tabular}{lllllll}
\hline \multirow{2}{*}{ Variables } & Codes & \multicolumn{2}{c}{ Levels } \\
& & $-\mathbf{2}$ & $-\mathbf{I}$ & $\mathbf{0}$ & $\mathbf{I}$ & $\mathbf{2}$ \\
\hline TRS $(\mathrm{g} / \mathrm{L})$ & $\mathrm{X}_{1}$ & 0 & 50 & 100 & 150 & 200 \\
Yeast extract $(\mathrm{g} / \mathrm{L})$ & $\mathrm{X}_{2}$ & 0 & 15 & 30 & 45 & 60 \\
Sodium acetate $(\mathrm{g} / \mathrm{L})$ & $\mathrm{X}_{3}$ & 0 & 5 & 10 & 15 & 20 \\
Salts of GYP $(\mathrm{mL} / \mathrm{L})$ & $\mathrm{X}_{4}$ & 0 & 2.5 & 5 & 7.5 & 10 \\
\hline
\end{tabular}

The association between the factors and response was modeled using polynomial equation given by Equation 3 , in which: $X_{1}, X_{2}$, $X_{3}$ and $X_{4}$ are the independent coded variables, $\beta_{0}, \beta_{1}, \beta_{2}, \beta_{3}, \beta_{4}, \beta_{12}$, $\beta_{13}, \beta_{14}, \beta_{23}, \beta_{24}$ and $\beta_{34}$ are the regression coefficients, and $\mathrm{Y}$ is the response function.

$$
\begin{aligned}
& Y=\beta_{0}+\beta_{1} X_{1}+\beta_{1} X_{1}^{2}+\beta_{2} X_{2}+\beta_{2} X_{2}^{2}+\beta_{3} X_{3}+\beta_{3} X_{3}^{2}+\beta_{4} X_{4} \\
& +\beta_{4} X_{4}^{2}+\beta_{12} X_{1} X_{2}+\beta_{13} X_{1} X_{3}+\beta_{14} X_{1} X_{4}+\beta_{23} X_{2} X_{3}+\beta_{24} X_{2} X_{4}+\beta_{34} X_{3} X_{4}
\end{aligned}
$$

\section{Analytical methodology}

For LA and sugars quantification it was used a high-performance liquid chromatography (HPLC) (Shimadzu, Prominence series) equipped with an ultra-violet detector at $210 \mathrm{~nm}$ and refractive index detector. The column used was Rezex ROA ( $300 \times 7.8 \mathrm{~mm})$ from Phenomenex, eluted with $5 \mathrm{mM}$ of $\mathrm{H}_{2} \mathrm{SO}_{4}$ as the mobile phase. The flow was $0.6 \mathrm{~mL} / \mathrm{min}$ and the injection volume was $5 \mu \mathrm{L}$. The temperature was set at $65^{\circ} \mathrm{C}$.

In order to determine the concentration and the isomeric purity of LA, HPLC was equipped with a Chirex 3126 column ( $150 \times 4.6 \mathrm{~mm})$ from Phenomenex and a UV detector. The flow was adjusted to $1 \mathrm{~mL} /$ min using $1 \mathrm{mM}$ of $\mathrm{CuSO}_{4}$ as the mobile phase and the temperature was fixed at $26^{\circ} \mathrm{C}$.

\section{Results}

The microorganism S. nakayamae subsp. nakayamae Vini6 is a natural producer of D-LA with a yield up to $50 \%$. The natural strain was able to produce $12.77 \mathrm{~g} / \mathrm{L}$ of LA from $20 \mathrm{~g} / \mathrm{L}$ glucose, with $92.01 \%$ of D-LA purity.

The natural strain was exposed to UV-light for 20minutes. After the first UV-light exposure originated the selected strain called Vini6 2x (second generation). This new strain was exposed to UV- 
light and generated the strain Vini6 3x (third generation). The UVlight cycle was repeated one more time and generated Vini6 $4 \mathrm{x}$ (fourth generation), Vini6 4x2 (fourth generation colony 2), Vini6 $4 \times 3$ (fourth generation colony 3), and Vini6 4x4 (fourth generation colony 4). In total, 6 strains were selected from UV-light exposure, which are depicted in Table 3. All selected strains presented a better D-LA production when compared to the natural strain. The highest LA production obtained from $100 \mathrm{~g} / \mathrm{L}$ of glucose was $88.98 \mathrm{~g} / \mathrm{L}$ using the selected strain S. nakayamae Vini6 2x, which was chosen as the strain to be used in the next tests.

Table $3 \mathrm{D}(-)$ acid lactic production by 6 strains submitted to UV mutation from $100 \mathrm{~g} / \mathrm{L}$ of glucose

\begin{tabular}{ll}
\hline Strain & D(-) lactic acid $(\mathbf{g} / \mathbf{L})$ \\
\hline S. nakayamae Vini6 natural strain & 60.64 \\
S. nakayamae Vini6 2x & 88.98 \\
S. nakayamae Vini6 3x & 76.9 \\
S. nakayamae Vini6 4x & 59.85 \\
S. nakayamae Vini6 4×2 & 81.95 \\
S. nakayamae Vini6 4×3 & 79 \\
S. nakayamae Vini6 4x4 & 79.68 \\
\hline
\end{tabular}

After the strain selection, D-LA production was tested using different carbon sources: sugarcane juice, clarified sugarcane juice, commercial glucose, and commercial sucrose. The highest D-LA production occurred in the presence of commercial sucrose as a carbon source, both after 24 and 48 hours (56.61 and $58.98 \mathrm{~g} / \mathrm{L}$, respectively). However, commercial sucrose has high market prices, which justifies its replacement by a more economically viable source of carbon. Therefore, it is noted the clarified sugarcane juice has a slightly higher production of D-LA $(53.80 \mathrm{~g} / \mathrm{L})$ when compared to sugarcane juice $(48.18 \mathrm{~g} / \mathrm{L})$. The clarification was performed in order to precipitate the largest possible amount of impurities, resulting in an improvement of the microorganism performance. The process did not affect the sucrose content, but pectin, albumin, mucilage, starch, fibres, waxes, proteins, pigments, and other components precipitated and were removed with a simple filtration. ${ }^{24}$ Front of the results clarified sugarcane juice was chosen as the carbon source to D-LA production.

The next step was to test different nitrogen sources to be used for D-LA production: yeast extract, yeast autolyzed, CSL, and pro-floo. The results of the nitrogen source influence in production, productivity and yield of D-LA are shown in Table 4. The highest D-LA production was $67.89 \mathrm{~g} / \mathrm{L}$ using yeast extract on the concentration B, after 24 hours of fermentation. Remaining TRS also presented the best result using yeast extract $(6.15 \mathrm{~g} / \mathrm{L})$ on the concentration B. Only when LA yield is considered, corn steep liquor presented the best result, reaching $0.75 \mathrm{~g} / \mathrm{g}$ after 48 hours of fermentation, also on concentration B. However, yeast extract also presented a good yield $(0.58 \mathrm{~g} / \mathrm{g})$, being chosen as the nitrogen source to be used for D-LA production.

An average value followed by different letters in vertical (lowercase) and horizontal (uppercase) differ at 5\% according to Tukey's test.

Based on the preliminary tests, clarified sugarcane juice and yeast extract were used in the central composite design in order to optimize the media composition for D-LA production. Table 5 shows the variables and the real concentrations of each component: TRS from clarified sugarcane juice $\left(X_{1}\right)$, yeast extract $\left(X_{2}\right)$, sodium acetate $\left(\mathrm{X}_{3}\right)$, and salts solution from GYP $\left(\mathrm{X}_{4}\right)$, as well as the average results obtained from a triplicate of D-LA production, productivity and remaining TRS after 24 hours of fermentation.

Table $4 \mathrm{D}(-)$ lactic acid production (g/L) after 24 and 48 hours of fermentation, remaining TRS $(g / L)$, and yield $(g / g)$, according to the nitrogen source used

\begin{tabular}{lcl}
\hline Nitrogen source & \multicolumn{1}{c}{ Concentration A } & Concentration B \\
Production - 24 hours & \\
\hline Yeast extract & $50.82 \mathrm{Ba}$ & $67.89 \mathrm{Aa}$ \\
Yeast autolyzed & $3.83 \mathrm{Ac}$ & $5.02 \mathrm{Ac}$ \\
Corn steep liquor & $37.60 \mathrm{Ab}$ & $39.13 \mathrm{Ab}$ \\
Pro-floo & $0.37 \mathrm{Ac}$ & $0.48 \mathrm{Ac}$ \\
Production - 48 hours & \\
Yeast extract & $50.92 \mathrm{Aa}$ & $54.83 \mathrm{Aa}$ \\
Yeast autolyzed & $1.24 \mathrm{Ab}$ & $1.82 \mathrm{Ab}$ \\
Corn steep liquor & $45.58 \mathrm{Ba}$ & $58.67 \mathrm{Aa}$ \\
Pro-floo & $0.13 \mathrm{Ab}$ & $0.47 \mathrm{Ab}$ \\
Remaining TRS - 48 hours & \\
Yeast extract & $12.61 \mathrm{Ab}$ & $6.15 \mathrm{Ab}$ \\
Yeast autolyzed & $55.89 \mathrm{Aa}$ & $62.00 \mathrm{Aa}$ \\
Corn steep liquor & $17.56 \mathrm{Ab}$ & $19.70 \mathrm{Ab}$ \\
Pro-floo & $57.55 \mathrm{Ba}$ & $68.99 \mathrm{Aa}$ \\
Yield - 48 hours & & \\
Yeast extract & $0.58 \mathrm{Aa}$ & $0.58 \mathrm{Ab}$ \\
Yeast autolyzed & $0.03 \mathrm{Ab}$ & $0.05 \mathrm{Ac}$ \\
Corn steep liquor & $0.55 \mathrm{Ba}$ & $0.75 \mathrm{Aa}$ \\
Pro-floo & $0.00 \mathrm{Ab}$ & $0.02 \mathrm{Ac}$ \\
\hline
\end{tabular}

The highest D-LA production was obtained in test 14, with $74.46 \mathrm{~g} / \mathrm{L}$ of LA produced from $150 \mathrm{~g} / \mathrm{L}$ of TRS, $45 \mathrm{~g} / \mathrm{L}$ of yeast extract, $5 \mathrm{~g} / \mathrm{L}$ of sodium acetate, and $7.5 \mathrm{~mL} / \mathrm{L}$ of GYP salts solution, as shown in Table 5. On these conditions, productivity and remaining TRS were $3.10 \mathrm{~g} / \mathrm{Lh}$ and $31.06 \mathrm{~g} / \mathrm{L}$. D-LA isomer purity presented an average of $97 \% \pm 2 \%$ between the 28 tests, showing that this microorganism may be suitable for an industrial process for D-LA production.

The application of multiple regression analysis for each response from Table 5 resulted in the regression Equations 4, 5 and 6. Equation 4 represents the regression model for LA production (LA), Equation 5 for productivity (P), and Equation 6 for remaining TRS (RTRS). $\mathrm{X}_{1}$, $\mathrm{X}_{2}, \mathrm{X}_{3}$ and $\mathrm{X}_{4}$ are the coded values of the test variables TRS, yeast extract, sodium acetate and GYP salts, respectively.

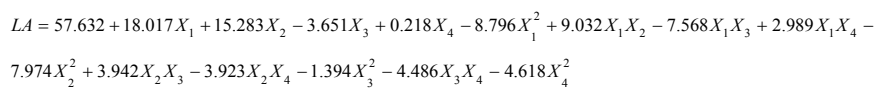

$P=2.640+0.527 X_{1}+0.651 X_{2}-0.160 X_{3}+0.002 X_{4}-0.499 X_{1}^{2}+$

$0.424 X_{1} X_{2}-0.198 X_{1} X_{3}+0.068 X_{1} X_{4}-0.495 X_{2}^{2}-0.036 X_{2} X_{3}-0.077 X_{2} X_{4}-0.275 X_{3}^{2}-0.224 X_{3} X_{4}-0.117 X_{4}^{2}$ 
$R_{\text {TRS }}=3.352+16.203 X_{1}-23.479 X_{2}+0.841 X_{3}-3.684 X_{4}+6.946 X_{1}^{2}-15.789 X_{1} X_{2}+5.253 X_{1} X_{3}-4.196 X_{1} X_{4}+19.503 X_{2}^{2}-5.534 X_{2} X_{3}+3.494 X_{2} X_{4}+3.921 X_{3}^{2}+7.242 X_{3} X_{4}+4.065 X_{4}^{2}$

Table 5 Central composite design (real values), and the results after 24 of fermentation

\begin{tabular}{|c|c|c|c|c|c|c|c|}
\hline \multirow[b]{2}{*}{ Test } & \multicolumn{4}{|c|}{ Concentration } & \multirow{2}{*}{$\begin{array}{l}\text { Production } \\
\text { (g/L) }\end{array}$} & \multirow{2}{*}{ Productivity (g/Lh) } & \multirow{2}{*}{ Remaining TRS (g/L) } \\
\hline & TRS & $\begin{array}{l}\text { Yeast } \\
\text { extract }\end{array}$ & Acetate & GYP salts & & & \\
\hline I & 50 & 15 & 5 & 2.5 & 1.37 & 0.06 & 46.58 \\
\hline 2 & 50 & 15 & 5 & 7.5 & 1.77 & 0.07 & 48.51 \\
\hline 3 & 50 & 15 & 15 & 2.5 & 7.48 & 0.31 & 36.97 \\
\hline 4 & 50 & 15 & 15 & 7.5 & 6.98 & 0.29 & 33.65 \\
\hline 5 & 50 & 45 & 5 & 2.5 & 4.92 & 0.2 & 33.94 \\
\hline 6 & 50 & 45 & 5 & 7.5 & 25.88 & 1.08 & 5.4 \\
\hline 7 & 50 & 45 & 15 & 2.5 & 36.53 & 1.52 & 2.83 \\
\hline 8 & 50 & 45 & 15 & 7.5 & 6.34 & 0.26 & 30.58 \\
\hline 9 & 150 & 15 & 5 & 2.5 & 3.36 & 0.14 & 138.58 \\
\hline 10 & 150 & 15 & 5 & 7.5 & 27.89 & 1.16 & 96.12 \\
\hline II & 150 & 15 & 15 & 2.5 & 8.92 & 0.37 & 132.14 \\
\hline 12 & 150 & 15 & 15 & 7.5 & 3.21 & 0.13 & 132.34 \\
\hline 13 & 150 & 45 & 5 & 2.5 & 73.49 & 3.06 & 28.91 \\
\hline 14 & 150 & 45 & 5 & 7.5 & 74.46 & 3.1 & 31.06 \\
\hline 15 & 150 & 45 & 15 & 2.5 & 58.51 & 2.44 & 45.79 \\
\hline 16 & 150 & 45 & 15 & 7.5 & 55.75 & 2.32 & 54.55 \\
\hline 17 & 0 & 30 & 10 & 5 & 3.93 & 0.16 & 0 \\
\hline 18 & 200 & 30 & 10 & 5 & 48.48 & 2.02 & 97.91 \\
\hline 19 & 100 & 0 & 10 & 5 & 1.4 & 0.06 & 100 \\
\hline 20 & 100 & 60 & 10 & 5 & 51.67 & 2.15 & 32.34 \\
\hline 21 & 100 & 30 & 0 & 5 & 63.39 & 2.64 & 3.16 \\
\hline 22 & 100 & 30 & 20 & 5 & 31.89 & 1.33 & 26.55 \\
\hline 23 & 100 & 30 & 10 & 0 & 64.27 & 2.68 & 4.92 \\
\hline 24 & 100 & 30 & 10 & 10 & 61.12 & 2.55 & 3.64 \\
\hline 25 & 100 & 30 & 10 & 5 & 66.58 & 2.77 & 4.15 \\
\hline 26 & 100 & 30 & 10 & 5 & 64.27 & 2.68 & 3.7 \\
\hline 27 & 100 & 30 & 10 & 5 & 61.05 & 2.54 & 3.93 \\
\hline 28 & 100 & 30 & 10 & 5 & 61.57 & 2.57 & 3.58 \\
\hline
\end{tabular}

The identification of significant parameters was performed through hypothesis test using t-Student statistic method. The probability was used as a tool to verify the significance of each coefficient. The maximum probability of error in the test was $5 \%$, thus the parameters with the value $\mathrm{p}<0.05$ were considered significant.

The main variables affecting production, productivity and remaining TRS are $X_{1}$ (TRS) and $X_{2}$ (yeast extract). Based on these results, it was possible to imply that acetate $\left(\mathrm{X}_{3}\right)$ and salts solution from GYP $\left(\mathrm{X}_{4}\right)$ were not essential for D-LA production using S. nakayamae Vini6 2x.

Fisher-test was used to analyse the statistical significance of the Equations 4, 5 and 6 through ANOVA, as shown in Table 6.
For Equation 4, $\mathrm{F}_{14,13}$ calculated (5.32) was higher than $\mathrm{F}_{14,13}$ tabulated (2.55) with $95 \%$ of confidence level, showing that the model is significant and adequately explains experimental data variation for LA production. The good fit of the model was verified by the determination coefficient $\left(\mathrm{R}^{2}\right)$ and multiple correlation co-efficient (R). In this case, the value of $\mathrm{R}^{2}$ indicates that $85 \%$ of the variability in the data was explained by the mathematical model. The high R-value (0.92) shows a high degree of agreement between the experimental data and predicted values (Table 6). Based on the mathematical model it was constructed the response surface for LA production in function of TRS $\left(\mathrm{X}_{1}\right)$ and yeast extract $\left(\mathrm{X}_{2}\right)$. To achieve high lactic acid concentrations, Figure 1A shows that the optimum concentration of TRS should be between 100 and $200 \mathrm{~g} / \mathrm{L}$ and between 30 and $60 \mathrm{~g} / \mathrm{L}$ for yeast extract. 
Table 6 ANOVA table for the responses with $95 \%$ of confidence level

\begin{tabular}{|c|c|c|c|c|c|}
\hline \multicolumn{6}{|l|}{ Production } \\
\hline Source of variation & Sum of Squares & Degrees of Freedom & Mean Square & $\mathbf{F}_{\text {calculated }}$ & $\mathbf{P}$ \\
\hline Regression & 19782.06 & 14 & 1.41 & 5.32 & 0.00232 \\
\hline Residues & 3453.05 & 13 & 265.62 & & \\
\hline Lack of fit & 3432.77 & 10 & 343.27 & & \\
\hline Pure error & 20.28 & 3 & 6.76 & & \\
\hline Total & 23235.11 & 27 & & & \\
\hline \multicolumn{6}{|l|}{$R^{2}=0.85 ; R=0.92$} \\
\hline \multicolumn{6}{|l|}{ Productivity } \\
\hline Regression & 3.18 & 14 & 2.27 & 7.82 & 0.000333 \\
\hline Residues & 378.25 & 13 & 0.29 & & \\
\hline Lack of fit & 374.91 & 10 & 0.37 & & \\
\hline Pure error & 0.03 & 3 & 0.01 & & \\
\hline Total & 3.56 & 27 & & & \\
\hline \multicolumn{6}{|l|}{$R^{2}=0.89 ; R=0.94$} \\
\hline \multicolumn{6}{|l|}{ Remaining TRS } \\
\hline Regression & 35426.3 & 14 & 2.53 & 4.94 & 0.00329 \\
\hline Residues & 6657.28 & 13 & 512.1 & & \\
\hline Lack of fit & 6657.11 & 10 & 665.71 & & \\
\hline Pure error & 0.18 & 3 & 0.06 & & \\
\hline Total & 42083.58 & 27 & & & \\
\hline$R^{2}=0.84 ; R=0.92$ & & & & & \\
\hline
\end{tabular}
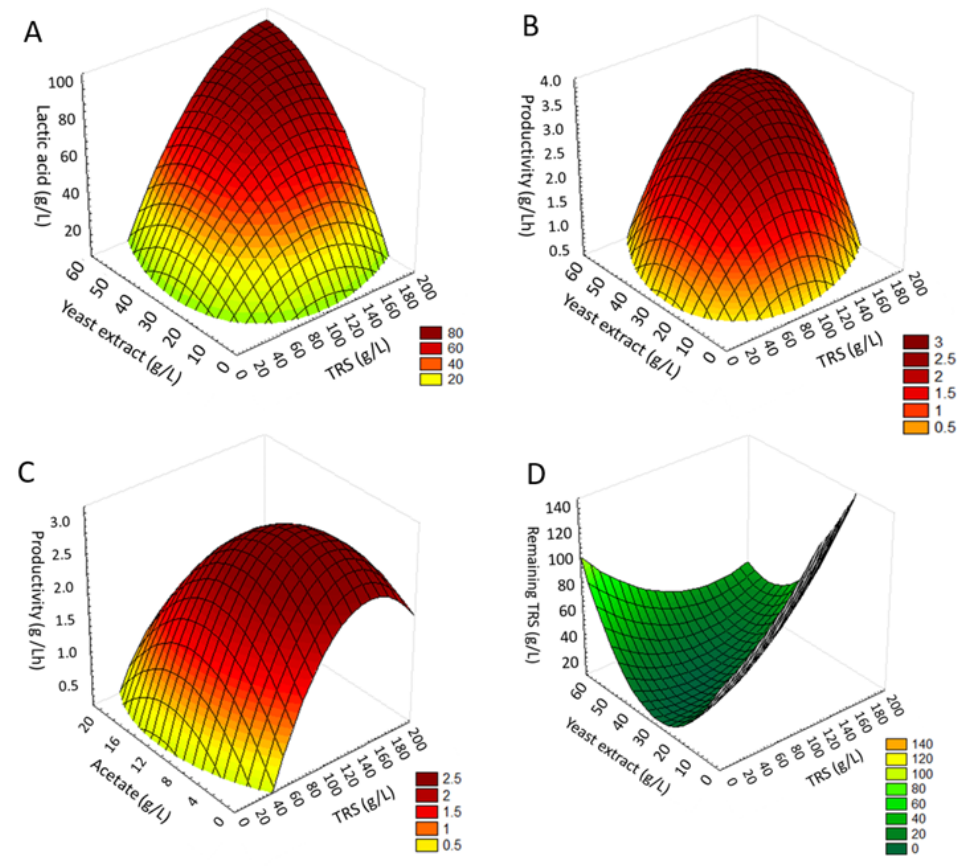

Figure I Response surface of $(A)$ lactic acid production in function of TRS $\left(X_{1}\right)$ and yeast extract $\left(X_{2}\right) ;(B)$ lactic acid productivity in function of TRS $\left(X_{1}\right)$ and yeast extract $\left(X_{2}\right)$; (C) lactic acid productivity in function of TRS $\left(X_{1}\right)$ and acetate $\left(X_{3}\right)$; and $(D)$ remaining TRS in function of TRS $\left(X_{1}\right)$ and yeast extract $\left(X_{2}\right)$. 
Considering the productivity (Equation 5) Fisher-test also confirmed that the mathematical model was predictive. $F_{14,13}$ calculated (7.82) was higher than $\mathrm{F}_{14,13}$ tabulated (2.55) with $95 \%$ of confidence level, showing that the model is significant. In this case, $\mathrm{R}^{2}$ indicated that $89 \%$ of the variability in the data was explained by the model. The high R-value (0.94) shows a high degree of agreement between the experimental data and predicted values (Table 6). Thus, it was possible to construct the response surface for LA productivity in function of TRS $\left(\mathrm{X}_{1}\right)$ and yeast extract $\left(\mathrm{X}_{2}\right)$ as shown in Figure 1B; and in function of TRS $\left(X_{1}\right)$ and acetate $\left(X_{3}\right)$ as shown in Figure 1C. According to Figures 1B and 1C, better productivities can be achieved when the concentrations of TRS are between 120 and $180 \mathrm{~g} / \mathrm{L}$ of TRS, yeast extract is between 35 and $55 \mathrm{~g} / \mathrm{L}$, and sodium acetate is between 4 and $10 \mathrm{~g} / \mathrm{L}$.

According to Equation 6, $\mathrm{F}_{14,13}$ calculated (4.94) was higher than $\mathrm{F}_{14,13}$ tabulated (2.55) with $95 \%$ of confidence level, showing that the mathematical model was significant and adequately explained the experimental data variation for LA yield. In this case, the value of $\mathrm{R}^{2}$ indicated that $84 \%$ of the variability in the data was explained by the model. The high R-value (0.92) also shows a high degree of agreement between the experimental data and predicted values (Table 6). Based on these results, Figure 1D shows that in order to obtain low amounts of remaining TRS, initial TRS concentrations should be around $100 \mathrm{~g} / \mathrm{L}$ and yeast extract should be $30 \mathrm{~g} / \mathrm{L}$.

In all cases, residual distribution responses were random around zero with no tendency. The observed values were close to those predicted, leading to a steady trend and a normal distribution.

In general, it was observed that high TRS concentration (up to $150 \mathrm{~g} / \mathrm{L}$ ) leads to a decrease in the productivity and a higher amount of remaining TRS. In this context, the best media composition for $\mathrm{S}$. nakayamae Vini6 2x should be composed by $150 \mathrm{~g} / \mathrm{L}$ of TRS from clarified sugarcane juice and $35 \mathrm{~g} / \mathrm{L}$ of yeast extract. $4 \mathrm{~g} / \mathrm{L}$ of sodium acetate could also be used as a complementary nutrient in order to enhance the productivity.

\section{Discussion}

Several microorganisms have been reported to be D-LA producers, such as Lactobacillus delbrueckii ${ }^{15}$ Lactobacillus coryniformis ${ }^{17}$ and Lactobacillus plantarum. ${ }^{10,14,18,19}$ Several $S$ porolactobacillus sp. strains have also been reported to be D-LA producers. ${ }^{16,22,25-33}$ Even though, D-LA production is still a challenge for the industry, ${ }^{12,13}$ once the majority of good LA producers have key-enzymes to L-LA production.

In this sense, many studies report the use of metabolic engineering tools to obtain higher D-LA production..$^{10,12,14,18-21,29,33,34}$ Instead of using metabolic engineering tools, this study presents a UV-light mutation approach to improve the D-LA production by S. nakayamae nakayamae. This kind of approach is widely used for mutation and selection of microorganisms in order to improve their capacity of producing biologically active substances. ${ }^{35,36}$ The use of UV-selection mechanism is an effective mutagenesis tool towards improving lactic acid production in different strains, as demonstrated for Lactobacillus lactis BME5-18 with a productivity $46 \%$ higher than the parent strain 37 and Rhizopus oryzae R1021 with an improvement of 52\% of LA production. ${ }^{36}$

Clarified sugarcane juice and yeast extract were the best carbon and nitrogen sources between the ones evaluated for D-LA production by S. nakayamae Vini6 2x.

Yeast extract had been chosen once yeast extract makes it possible to have a faster D-LA production. A study using $S$. inulinus detected that the free amino acids are the limiting factor for the lactic acid production 30. It turned out that this is the reason why yeast extract is a good nitrogen source for this microorganism. Furthermore, Brazil has a high potential of using the remaining yeast from the ethanol industry to produce yeast extract with low costs. As highlighted by Pleissner et al., ${ }^{38}$ the costs of biotechnological inputs are region dependent. For instance, in the case presented here, yeast extract can be an important input if the LA production could be done close to an ethanol and yeast production plant, in a biorefinery concept. Ethanol fermentation as it is done in Brazilian distilleries generates an excess of $20 \mathrm{~kg}$ of dried yeast per $1000 \mathrm{~L}$ of produced ethanol ${ }^{39}$ that can be converted to a low-cost yeast extract. This process is already costeffective in Brazilian scenario. ${ }^{40}$ As an example, a Sugarcane $1^{\text {st }}$ Generation Biorefinery would process sugarcane to sucrose, ethanol, yeast products and LA. The remaining bagasse can be still used to provide steam and electricity to sustain processes and the excess of electricity available can be even exported to the grid.

Regarding the optimization process, the main components affecting D-LA production by S. nakayamae Vini6 $2 \mathrm{x}$ are clarified sugarcane juice and yeast extract. Higher D-LA concentrations can be obtained using $150 \mathrm{~g} / \mathrm{L}$ of TRS from clarified sugarcane juice and $35 \mathrm{~g} / \mathrm{L}$ of yeast extract. $4 \mathrm{~g} / \mathrm{L}$ of sodium acetate can also be used as a complementary nutrient in order to enhance the productivity. Zheng et al. ${ }^{32}$ proved that the presence of sodium ions in the early growth phase of $S$. inulinus improve the productivity of D-LA by the keyenzyme phosphofructokinase. Besides, sodium acetate is also known as an efficient medium component to prevent the contamination of the process by fungi. ${ }^{41}$

\section{Conclusion}

S. nakayamae Vini6 $2 \mathrm{x}$ is a useful strain to produce D-LA with high purity $(\approx 97 \%)$. UV-light is a suitable tool for increasing the LA production, as well as keeping a high isomeric purity. The use of central composite design was a useful tool to optimize the production process of D-LA. Further, the obtained results are very promising for scaling-up the fermentation process. As next steps, it is intended to scale-up the fermentation process in order to obtain higher D-LA production and productivity.

\section{Acknowledgements}

None.

\section{Funding details}

Fundação de Amparo à Pesquisa do Estado de São Paulo - FAPESP $(2012 / 21679-9)$

\section{Conflict of interest}

Author declares that there is no conflict of interest.

\section{References}

1. Auras R, Lim LT, Selke SEM, et al. Poly (Lactic Acid): Synthesis, Structures, Properties, Processing, and Applications. In: Grossman RF, Nwabunma D, editors. New Jersey: John Wiley \& Sons, Inc.; 2010. 
2. Vijayakumar J, Aravindan R, Viruthagiri T. Recent trends in the production, purification and application of lactic acid. Chem Biochem Eng Q. 2008;22(2):245-264.

3. Zhou S, Causey TB, Hasona A, et al. Production of optically pure D-lactic acid in mineral salts medium by metabolically engineered Escherichia coli W3110. Appl Environ Microbiol. 2003;69(1):399-407.

4. Ghaffar T, Irshad M, Anwar Z, et al. Recent trends in lactic acid biotechnology: A brief review on production to purification. Journal of Radiation Research and Applied Sciences. 2014;7(2):222-229.

5. Juodeikiene G, Vidmantiene D, Basinskiene L, et al. Green metrics for sustainability of biobased lactic acid from starchy biomass vs chemical synthesis. Catalysis Today. 2015;239:11-16.

6. Farah S, Anderson DG, Langer R. Physical and mechanical properties of PLA, and their functions in widespread applications-A comprehensive review. Advanced Drug Delivery Reviews. 2016;107:367-392.

7. Södergård A, Stolt M. Properties of lactic acid based polymers and their correlation with composition. Progress in Polymer Science. 2002;27(6):1123-1163.

8. Oh H, Wee YJ, Yun JS, et al. Lactic acid production from agricultural resources as cheap raw materials. Bioresour Technol. 2005;96(13):1492-1498.

9. Ikada Y, Jamshidi K, Tsuji H, et al. Stereocomplex formation between enantiomeric poly (lactides). Macromolecules. 1987;20(4):904-906.

10. Hama S, Mizuno S, Kihara M, et al. Production of D-lactic acid from hardwood pulp by mechanical milling followed by simultaneous saccharification and fermentation using metabolically engineered Lactobacillus plantarum. Bioresour Technol. 2015;187:167-172.

11. Alves de Oliveira R, Komesu A, Vaz Rossell CE, et al. Challenges and opportunities in lactic acid bioprocess design-From economic to production aspects. Biochemical Engineering Journal. 2018;133:219-239.

12. Yamada R, Wakita K, Mitsui R, et al. Enhanced D-lactic acid production by recombinant Saccharomyces cerevisiae following optimization of the global metabolic pathway. Biotechnol Bioeng. 2017;114(9):2075-2084.

13. Klotz S, Kaufmann N, Kuenz A, et al. Biotechnological production of enantiomerically pure D-lactic acid. Appl Microbiol Biotechnol. 2016;100(22):9423-9437.

14. Zhang Y, Vadlani PV, Kumar A, et al. Enhanced D-lactic acid production from renewable resources using engineered Lactobacillus plantarum. Appl Microbiol Biotechnol. 2016;100(1):279-288.

15. Zhang Y, Vadlani PV. D-Lactic acid biosynthesis from biomass-derived sugars via Lactobacillus delbrueckii fermentation. Bioprocess Biosyst Eng. 2013;36(12):1897-1904.

16. Wang L, Zhao B, Li F, et al. Highly efficient production of D-lactate by S_porolactobacillus sp. CASD with simultaneous enzymatic hydrolysis of peanut meal. Appl Microbiol Biotechnol. 2011;89(4):1009-1017.

17. Yáñez R, Moldes AB, Alonso JL, et al. Production of $\mathrm{D}(-)$-lactic acid from cellulose by simultaneous saccharification and fermentation using Lactobacillus coryniformis subsp. torquens. Biotechnol Lett. 2003;25(14):1161-1164.

18. Zhang Y, Kumar A, Hardwidge PR, et al. D-lactic acid production from renewable lignocellulosic biomass via genetically modified Lactobacillus plantarum. Biotechnol Prog. 2016;32(2):271-278.

19. Yoshida S, Okano K, Tanaka T, et al. Homo-D-lactic acid production from mixed sugars using xylose-assimilating operon-integrated Lactobacillus plantarum. Appl Microbiol Biotechnol. 2011;92(1):67-76.

20. Liu Y, Gao W, Zhao X, et al. Pilot scale demonstration of D-lactic acid fermentation facilitated by $\mathrm{Ca}(\mathrm{OH}) 2$ using a metabolically engineered Escherichia coli. Bioresour Technol. 2014;169:559-565.

21. Wang Y, Tian T, Zhao J, et al. Homofermentative production of Dlactic acid from sucrose by a metabolically engineered Escherichia coli. Biotechnol Lett. 2012;34(11):2069-2075.

22. Beitel SM, Sass DC, Coelho LF, et al. High D(-) lactic acid levels production by S_porolactobacillus nakayamae and an efficient purification. Annals of Microbiology. 2016;66(4):1367-1376.

23. Kozaki M, Uchimura T, Okada S. Experimental Manual of Lactic Acid Bacteria. Tokio: Asakura Syoten; 1992.

24. Prati P, Moretti RH. Study of clarification process of sugar cane juice for consumption. Ciência e Tecnol Aliment. 2010;30(3):776-783.

25. Fukushima K, Sogo K, Miura S, et al. Production of D-lactic acid by bacterial fermentation of rice starch. Macromol Biosci. 2004;4(11):1021-1027.

26. Zhao B, Wang L, Li F, et al. Kinetics of D-lactic acid production by $\mathrm{S}$ porolactobacillus sp. strain CASD using repeated batch fermentation. Bioresour Technol. 2010;101(16):6499-6505.

27. Bai Z, Gao Z, Sun J, et al. D-lactic acid production by S_porolactobacillus inulinus YBS1-5 with simultaneous utilization of cottonseed meal and corncob residue. Bioresour Technol. 2016;207:346-352.

28. Zhao T, Liu D, Ren H, et al. D-lactic acid production by S porolactobacillus inulinus Y2-8 immobilized in fibrous bed bioreactor using corn flour hydrolyzate. J Microbiol Biotechnol. 2014;24(12):1664-1672.

29. Sun J, Wang Y, Wu B, et al. Enhanced production of D-lactic acid by $\mathrm{S}$ porolactobacillus sp.Y2-8 mutant generated by atmospheric and room temperature plasma. Biotechnol Appl Biochem. 2015;62(2):287-292.

30. Klotz S, Kuenz A, Prüße U. Nutritional requirements and the impact of yeast extract on the D-lactic acid production by $\mathrm{S}$ porolactobacillus inulinus. Green Chem. 2017;19(19):4633-4641.

31. Bai Z, Gao Z, He B, et al. Effect of lignocellulose-derived inhibitors on the growth and D-lactic acid production of S_porolactobacillus inulinus YBS1-5. Bioprocess Biosyst Eng. 2015;38(10):1993-2001.

32. Zheng L, Liu M, Sun J, et al. Sodium ions activated phosphofructokinase leading to enhanced D-lactic acid production by $\mathrm{S}$ porolactobacillus inulinus using sodium hydroxide as a neutralizing agent. Appl Microbiol Biotechnol. 2017;101(9):3677-3687.

33. Zheng H, Gong J, Chen T, et al. Strain improvement of S porolactobacillus inulinus ATCC 15538 for acid tolerance and production of D-lactic acid by genome shuffling. Appl Microbiol Biotechnol. 2010;85(5):1541-1549.

34. Ou MS, Awasthi D, Nieves I, et al. Sweet sorghum juice and bagasse as feedstocks for the production of optically pure lactic acid by native and engineered Bacillus coagulans strains. BioEnergy Research. 2016;9(1):123-131.

35. Goodarzi A. UV - Induced mutagenesis in lactic acid bacteria. Int J Genet Genomics. 2016;4(1):1-4.

36. Bai DM, Zhao XM, Li XG, et al. Strain improvement of Rhizopus oryzae for over-production of $\mathrm{L}(+)$-lactic acid and metabolic flux analysis of mutants. Biochemical Engineering Journal. 2004;18(1):41-48.

37. Bai DM1, Zhao XM, Li XG, et al. Strain improvement and metabolic flux analysis in the wild-type and a mutant Lactobacillus lactis strain for $\mathrm{L}(+)$ lactic acid production. Biotechnol Bioeng. 2004 Dec 20;88(6):681-689.

38. Pleissner D, Dietz D, van Duuren JB, et al. Biotechnological production of organic acids from renewable resources. Advances in Biochemical Engineering/Biotechnology. Springer, Berlin, Heidelberg; 2017. p. 1-38. 
39. Sgarbieri VC, Alvim ID, Vilela ESD, et al. Pilot plant production of yeast (Saccharomyces sp.) derivatives for use as ingredients in food formulations. Brazilian J Food Technol. 1999;2:119-125.

40. Alves de Oliveira R, Vaz Rossell CE, Lunelli BH, et al. Different strategies to improve lactic acid productivity based on microorganism physiology and optimum operating conditions. Ind Eng Chem Res. 2018;57(31):10118-10125.
41. Cortés-Zavaleta O, López-Malo A, Hernández-Mendoza A, et al Antifungal activity of lactobacilli and its relationship with 3-phenyllactic acid production. Int J Food Microbiol. 2014;173:30-35. 